\title{
Horseshoes, angels and other UFOs: Rethinking faith in light of present-day superstitions
}

\begin{abstract}
Author:
Cornel W. du Toit ${ }^{1}$

Affiliation:

${ }^{1}$ Research Institute for Theology and Religion, University of South Africa, South Africa

Correspondence to: Cornel du Toit

Email:

dtoitcw@unisa.ac.za

Postal address:

PO Box 392, UNISA 0003,

South Africa

Dates:

Received: 09 Dec. 2009

Accepted: 05 May 2011

Published: 08 Sept. 2011

How to cite this article:

Du Toit, C.W., 2011,

'Horseshoes, angels and

other UFOs: Rethinking

faith in light of present-

day superstitions', Verbum

et Ecclesia 32(1), Art. \#488,

9 pages. doi: $10.4102 /$

ve.v32i1. 488
\end{abstract}

(C) 2011. The Authors

Licensee: OpenJournals

Publishing. This work

is licensed under the

Creative Commons

Attribution License.
The monotheistic religions see God as the author of human faith. Faith comes 'from above' and as such is unnatural or supernatural. The faith of pagans, by contrast, is regarded as superstition and hence natural $(\mathrm{Rm} 1)$. One can make a case for the 'natural' universal incidence of both religion and superstition and their fulfilment of similar needs. In addition both are characterised by the pattern-finding operation of the human brain. The (causal) connections we make and the patterns we impose on reality have always helped people to comprehend and manipulate the world. Historical circumstances led to the development of 'official' religions as institutions wielding political power, whereas superstition has remained a para-religious phenomenon to this day.

But how should religion and superstition be viewed in a postmetaphysical, technoscientific environment? How can the supernatural aspects of religion and superstition be accommodated in such an environment? The role of affect and belief (placebo effect) in religion and superstition is also scrutinised. Viewed differently, both religion and superstition are considered natural and are proposed as a form of immanent transcendence, in which the 'supernatural' is not posited as a metaphysical model but is worked out 'from below' in terms of the human constitution.

\section{The 'unnaturalness' of religion and superstition}

The object of this article is to probe the relation between religious faith and superstition by examining superstition, assessing it and comparing its character with that of faith. There has been a spate of recent publications demonstrating the absurdity or unnaturalness of both phenomena (Claassen 2007; Dennett 2006; Dawkins 2006; Harris 2004; Park 2008; Shermer 2004). Most of them cite instances of the irrationality of faith and superstition without inquiring why both persist unabated throughout the modern world and people obstinately cling to beliefs that are illogical, irrational and self-embarrassing.

In terms of the neo-atheistic worldview both religion and superstition are unnatural in the sense that they do not fit into our empirically knowable, scientifically explicable world. Both accept realities that either do not exist or whose existence is not demonstrable (e.g. miracles, angels and demons, ghosts, life after death, unseen forces operating from afar, objects with inherent magical power, etc.). More especially scientists are cynical about the way religion and superstition seek to manipulate these 'realities', evidenced by belief in the instrumental power of prayer, crystals, rituals, fasting, charms and the like to achieve effects like good luck, healing, fertility, and averting misfortune, illness, drought and possession by evil spirits. Scientists consider such practices irrational in that there is no way of proving that a particular act, ritual or behaviour is connected with the supposed consequence. In this sense religion is irrational. Hence we must distinguish between faith in and acceptance of metaphysical entities on the one hand, and their impact on human lives on the other. The proposition that such forces exist cannot be verified or falsified. To some extent their supposed effects can.

You are what you believe, that is you are and are governed by what you take to be true. What we believe to be true is partly determined by the meaning we ascribe to our beliefs. We believe not merely in the world around us but also in a world beyond or 'above' us - a supernatural world. It is this 'natural' acceptance of the supernatural that comes under fire from the side of some natural scientists. The supernatural world is the realm of our beliefs and superstitions, metaphysical systems and mental constructs. But who and what determine what forms part of the natural world and what pertains to the supernatural worlds that people believe to be true? Who dictates the norms of what is considered natural or supernatural - science, philosophy, religion, tradition, 
culture? Or is it determined by our experience of the world we live in, characterised as it is (in a Western perspective) by a particular form of economic and technocratic rationality?

We evolved from the large hominids and the development of the neocortex ushered in a new phase of human consciousness. It marked the beginning of noninstinctual, conscious dealing with and duplication of reality. From the start of human consciousness the enigma of reality was linked with the question of causation: why do things happen, who or what causes them to happen, and why? ${ }^{1}$ These are epistemological questions: a desire to know and explain, and indirectly, a cry for knowledge. Thus epistemology was integral to human thought from the outset, even if its early forms rested on mistaken views of causation (positing supernatural realities as explanatory principles) and used metaphors, personification, animism, anthropopathy and the like to further the process. From the outset patterns were imposed on a perplexing world so as to make sense of it and satisfy the human need for self-protection, advantage, certainty and security. From the outset people claimed monopolies on knowing what the correct interpretation of reality was. This included supernatural (superstitious) reality well into the era of scientific modernism. Initially the two worlds were one. ${ }^{2}$

The greater part of human cultural history is steeped in superstition. The earliest human societies worked with models that posited supernatural realities to compensate for defective insight into causal connections. The causal connections were not illogical, but they had to invoke gods, demons, animated nature, et cetera to justify themselves. Since then the situation has changed greatly. Explanations and causal connections must accord with our scientific worldview and the need to construct gods (the deus ex machina factor) has diminished. Yet it still does not prevent many people from harnessing supernatural powers to round off the picture. Apparently the role of the supernatural has become so entrenched over millennia that it is by now all but indispensable. In a closed scientific worldview any invocation of supernatural factors to account for things is primitive and unscientific, and that applies to religious beliefs and superstitions alike. Yet even rigid positivists cannot expunge the role of the subject and her experience, imagination, emotions and unconscious associations from the practice of 'pure' science. ${ }^{3}$

1.Hume (1963:40) describes the 'theatre' of the world as experienced by our first ancestors, in which they were ignorant of the causes of things, as follows: 'These unknown causes, then, become the constant object of our hope and fear; and while the passions are kept in perpetual alarm by an anxious expectation of events, the imagination is equally employed in forming ideas of those powers, on which we have so entire a dependence'

2.It may be reductive to attribute the success of beliefs and practices that persist to this day to their supposed evolutionary value for human survival (e.g. Sloan Wilson's emphasis on group selection - see his Darwin's cathedral; also see Dawkins 2006:166ff). Some customs may have arisen simply because they appeal to people 2006:166ff). Some customs may have arisen simply because they appeal to people and make sense for one reason or another. But things don't necessarily have survival value just because they 'make sense'. Dennett $(2006: 156)$ underscores this: '[W]e need to remind ourselves that a benefit to human genetic fitness is not the same thing as a benefit to human happiness or human welfare'. James
rejects out of hand the notion that religion helps us to survive better.

3.For Hegel (1959:84), 'if the story of the sciences is absolutized, science degenerates into scientism'.

\section{When is a belief a superstition?}

The answer is not easy. Every culture has its myths and folklore about the origin of things and phenomena. They are not seen as superstitions, because we do not take them literally. Neither do we want to lose them, for it would mean losing a big part of our cultural heritage. But there are conditions. We do not blame a child for believing that the mouse collects its tooth from a shoe, but we would consider it ridiculous for an adult to do so. We do not blame adults for playing the lottery and believing that they will win. But we will think them silly if they refuse to walk in the veld for fear of a storm and being struck dead by lightning - even though the chances of being struck by lightning may be greater than those of winning the lottery. For some believers a slack student praying to pass his or her examination turns faith into superstition, but one who prays to be healed of an aggressive cancer is not superstitious. It is a matter of selective rationality. The science-religion debate is a case in point. What is the role of selective rationality in this context? Undeniably, a major reason for the debate is the fact that science offers plausible explanations of the origin and functioning of the cosmos, which had been the preserve of religion for many centuries.

\section{Homo sapiens: A pattern-finding being}

We can distinguish between 'soft' superstition that is not really taken seriously (walking under a ladder) and more serious or 'hard' superstition that assumes cultic dimensions (witchcraft). Even though we may speak tongue in cheek about soft superstitions, many people still cherish them, because they believe them to affect their well-being, good luck or misfortune. The actual issue is logical and rational, but the way it is substantiated by superstition is not. ${ }^{4}$

Superstitions are based on interpretations of 'signs' or things that befall you, actions that secure benefits and avert harm, as well as by linking issues which are quite unrelated (the post hoc ergo propter hoc argument that establishes a causal connection between two temporally sequential events - see Hume 1978:173-5, 405). Overall they concern a relationship with superior, extraneous forces and what one can do to harness these to one's benefit or to ward off harmful consequences. There are numerous examples of how our earliest forebears had to resort to this technique to make their life world comprehensible and manageable. Lewis defines superstition as follows:

It is generally held that superstition is the uneducated man's inheritance of the traditional beliefs of his ancestors based on the ignorance and irrational fear surrounding the great mysteries of life.

(Lewis 1975:8, 9)

Smith (2008) points out that:

... at the most general level superstitions serve, variously, to create a sense of predictability in an uncertain environment, to help people deal with feelings of powerlessness, to cope with

4.Hume (1963:96) puts it thus: 'Even the contrarieties of nature ... become proofs of some consistent plan, and establish one single purpose or intention, however inexplicable and incomprehensible'. 
personal or collective loss, or to create a sense of assurance as they pass through critical rites of passage.

(Smith 2008:43)

The human brain is structured to detect patterns everywhere and to relate issues and things without necessarily having good grounds for it: 'Our ability to make sense of the world begins with the marvellous ability of the human brain to pick out patterns in the information collected by our senses' (Park 2008:29). Human beings operate via relationships; otherwise their cognitive abilities would not exist. In fact, relating disparate things is typical of both language and thought. Brain operations can be translated into creative synaptic connections that establish relationships. Our thinking is structured metaphorically and these metaphoric processes determine our cognitive capacities and brain development (Lakoff \& Johnson 1999:45-59; 118ff).

Hence it is not surprising that throughout its evolution, human cognition hinged on discerning relationships, even if they necessitated supernatural forces. ${ }^{5}$ The metaphoric character of these relations makes it an open process. No predetermined norm (apart from emotional factors like suspicion, fear, prejudice and desire) dictates the nature of the relationship. People simply have a need for it, and this need is basic to superstition: establishing relations where no relationship exists (or is readily demonstrable) in order to make us feel 'better' at some level.

When reality per se does not provide sufficient signs ${ }^{6}$ to warrant seeing relationships (i.e. does not permit what we would now call empirically based, logical connections) people look for relations at a meta-empirical level, a metaworld they need to create in order to discern meaning. Just as human dreams, ideals, hopes and interpretations are expressed in novels, so at a more real level our will to impose meaning on our world emerges in a body of entrenched superstitions and the ongoing creation of new ones. Put differently, superstitions and beliefs are vehicles of meaning attributed to our existential experience and hopes. Their matrix is our real-life experiences, which we perceive as causally linked but which are also 'semiotically polysemous', thus permitting the establishment of 'arbitrary' relations. To this day we try to account for interpersonal conflict by constructing explanations (that are not provable and often off the mark). Just as we discern (impose) patterns to suit ourselves, so we organise our arguments and justifications to suit our (often irrational) sentiments. Usually we look for proofs or examples to support our intuitive feelings about everything from race, culture and religion to everyday trivialities. We organise our arguments in a (usually causal) pattern that we find irrefutable. This is the level at which people tend to disagree, because they spot different relationships or

5.Jahoda (1969:35) cites John Stuart Mill, who speaks of laws of association: "The principles of association are excellent in themselves, and indeed absolutely essential to the working of the human mind. Legitimately they yield science; illegitimately applied they yield magic, the bastard sister of science'.

6.Augustine related his notion of superstition to his doctrine of signs: 'Signs ... are things whose significance exceeds their sensory appearance and are used to communicate' (Smith 2008:13). He distinguished natural signs (like smoke) from conventional signs (calligraphy and music). Superstitions fall under conventional conventional signs (calligraphy and music). Superstitions fall under conventional
signs and can be harmful, because they are a medium of communication that can put people in contact with demons. interpret given facts to arrive at a different conclusion. Seen thus, superstition must be considered 'natural', because it offers semiotic support for what people choose to believe anyway.

If ordinary reality does not allow scope for meaningful relations to answer our questions, we create a semiotic space that serves as a symbolic mirror of reality. Examples are the positions of planets and stars (astrology), numeric patterns (numerology), animals' livers (hepatoscopy), the flight of birds, tealeaves in a cup, cloud patterns, and the fall of bones or arrows (divination).

In the religious domain the 'semiotically polysemous' sphere that allows us to establish relations are sacred scriptures. The stories recounted in these texts are used metaphorically to shape new meaning, meaning which again has a patterned validity; the difference being that in this instance divine authority backs it. We constantly exceed the fixed interpretive spaces. A case in point is the importance that believers attach to the theodicy issue, the underlying drive being their need to find a pattern. They do not want to be told that catastrophes are natural and coincidental; for that precludes the creation of the meaningful pattern they need to see or hear. Their lives must proceed according to a fixed plan, a purpose. A rational explanation of catastrophes is ruled out, for it robs them of the belief that these events are wrought by powers (with whom the believer can bargain).

\section{Faith is unnatural, superstition is natural Unnaturalness of faith}

Faith, at least in Reformed Christian circles, is not a human accomplishment but a gift from God (Eph 2:8; 2 Th 2:13). ${ }^{7}$ By nature people have some knowledge and awareness of God, but that at best leads to idolatry (superstition) rather than (true) faith (Rm 1:19-23; also see Calvin Institutes I/1 \& 3). ${ }^{8}$ In the New Testament the term 'faith' is largely defined by the semantic field of 'believing something to be true', only what you believe to be true is something you cannot see $(\mathrm{Hb} 11: 1)$. Even if you could see the historical Jesus, you still would not see that he is the son of God, just as you cannot see that liver parasites mean that you will win the war. You must believe it to be true. ${ }^{9}$ Here both superstitious people and believers fall back on the human brain's capacity to appropriate what is imperceptible to the senses (cf.

7.In the Old Testament, too, it is God who calls Abraham and eventually Israel to nationhood, not their own initiative (Gn 12:1-2; Hs 11:1; Am 9:7).

8.The problem with any absolute system like Calvin's is that you inevitably come a cropper. Calvin's consistency in constructing his system (metaphysics) within the confines of Pauline theology is admirable. But the implication that has made Calvinism widely unpopular is the notion that Christ's redemption is limited to the few elect who will be saved inevitably by God's grace through no doing of their own - everybody else deserves the punishment that awaits them. Hence it is a relentlessly deterministic system, cruel in the insecurity it creates and the terror it inspires, all covered by God's inexplicable love for a handful of elect souls (see Calvin's Institutes, II/15, 21, 24). See Hume $(1963: 89, n 6)$ for a critique of the doctrine of predestination.

9.The 'seeing as' component precedes the 'believing to be true' component. It is a basic metaphoric movement. In metaphor something is seen as something else and the resultant meaning is considered true. That makes it possible to experience what the resultant meaning is considered true. That makes it possible to experience what
we believe to be true. I see the host as Christ's body and believe it to be true. It enables me to have a particular experience when I take communion. 
accommodation theory). In Christianity; however, the belief that Christ is the son of God who came to save humankind via supernatural power (the Spirit) is enacted in a religious community and the accompanying rites. If you accept these as true, you are rewarded with diverse experiences. The way God accomplishes faith in human beings is through divine transformation (the born-again metaphor). The fact that people understand religious information using the same rational powers as they use to understand everything else does not detract from religion's claim to unique status, which should not be equated with other knowledge.

By claiming that religion is 'unnatural', 'true' faith is screened off from heresies, beliefs and superstition. That leaves faith (and the concomitant dogma) unimpeachable. My faith must be true, for it does not come from me. So anyone who attacks my religion is attacking the true God. This type of argument can take many different forms. Religions are mutually antagonistic and each writes the other off as heresy or superstition. Adherents of different religions often have more in common at the level of their superstitions than of their faith: belief in a goddess of chance, communication with the dead, witchcraft, astrology and the like cut across religious boundaries.

Even though religion is screened off from superstition, the churches have produced their fair share of superstitions. These are tolerated when they operate within the context of an accepted faith. Provided the basic dogmas of the faith are not questioned, they can be 'augmented' with 'religious experiences' that are, in the final analysis, plain superstition. Classical examples are the role of relics in the Catholic Church, stigmata of the cross (James 1994:545) and tales about saints and statues. In Protestantism the equivalents would be experiences of healing, visions and dreams. Superstition is not necessarily the result of ignorance and underdevelopment, as is commonly claimed (for superstition amongst educated church members, see Lewis 1975:135). If they think 'logically', most people would realise that superstition is just that: superstition (like their chances of winning the lotto). Superstition is not rational thought. Nonetheless, it is caused not by ignorance, but by the human need for it. ${ }^{10}$ Just as faith, defined as sure knowledge, presupposes firm trust in something, so superstition requires sure knowledge about something and firm trust in its efficacy. The aim of the argument is not to justify ignorance (superstition), but to understand it and to show how everybody's actions are determined, to a greater or lesser extent, by irrationalities. Superstition moreover has an element of entertainment and tickles the imagination. None of us believes the latest urban myth, but we all like to hear and discuss it. A cardinal urban myth is that scientists have no superstitions of their own.

10.Must superstitions be judged by analogy with different cultures? Surely not but neither can they be appraised from a dizzy height of superior modernistic knowledge. Here Wittgenstein sets an example when he identifies motifs in Frazer's fascinating book, The golden bough (1890). Wittgenstein (1979:1-2) shows that however strangely people may behave (especially what strikes us as primitive acts), it is not necessarily unintelligent; that mistakes are corrected; and that (weird) practices are probably found in other localities as well. Importantly, he attaches positive value to the patterns people discern and the value they attach to these: 'That ... everything a man perceives year in, year out around him, connected together in any variety of ways - that all should play a part in his thinking (his together in any variety of ways - that all should play a part in his thinking (his
philosophy) and his practices, is obvious, or in other words that is what we really know and find interesting' (Wittgenstein 1979:6; also see p. 8).
The Protestant churches and the Enlightenment were the first to react dramatically against superstition:

With the Reformation, Protestants unleashed a ferocious onslaught on superstitions of all kinds, massively expanding the category to embrace rituals that had hitherto been central elements of Christian orthodoxy, such as the seven sacraments, the invocation of saints, masses for the dead, vows and fasting.

(Smith 2008:21-22)

Higher criticism exposed the historical, cultural, geographical and anthropological restrictions on the Bible. We now know that faith and superstition cannot be separated in watertight compartments. But where does superstition end and faith begin? ${ }^{11}$ We know that elements of all neighbouring 'pagan' cultures were assimilated into the Bible and early church theology. ${ }^{12}$

The challenge to faith today is to maintain its credibility in the face of dominant techno science that questions fundamental religious assumptions. How can we resolve the naturalism-supernaturalism dichotomy in a postmetaphysical age? The rise of secular spirituality in itself may be an example of the emergence of immanent transcendence, which does not present the 'supernatural' as a metaphysical model but works it out 'from below' in terms of the human constitution. Typically it eliminates all dualisms and incorporates rationality and affect. Two models that seek to resolve the dilemma centre on the roles of reason (Hegel's Geist) and experience (Schleiermacher's feeling; James's experience). ${ }^{13}$

\section{Naturalness of superstition}

Calling religion, superstition or science 'natural' obviously depends on what we mean by natural. If it means that which accords with known laws of nature and which is scientifically demonstrable, it clearly excludes the supernatural, and hence religion and superstition. If we take a broader view of human behaviour in a cultural context, we must take it to be natural in the sense of intelligent beings' response to understanding and interacting with their world ${ }^{14}$ (i.e. analogous to the assumption of cultural diversity and that one culture cannot serve as a yardstick for another because there is no such thing as a standard culture). Over the ages people have looked down on foreign beliefs from their familiar world and denigrated the other as superstitious, pagan or savage. Our

11.Smith (2008:30ff) points out that in the 19th century exploration of English folklore magic, religion and science were seen as successive phases in an evolutionary magic, religion and science were seen as successive phases in an evolutionary
paradigm of human cognitive development. He also indicates (Smith 2008:31) that paradigm of human cognitive development. He also indicates (Smith 2008:31) that of thought, arguing that civilized thinking was rational, logical, and scientific, of thought, arguing that civilized thinking was rational, logical, and scientific,
whereas primitive thinking was affective, poetical and magical'. We know; however, that religion does not put an end to magic and superstition; neither does science mean the end of religion. It is equally inconceivable that the poetic and affective dimensions have disappeared from the modern mind.

12.These had to be dealt with from the outset: '[S]ometimes they took over pagan ritual and "Christianised" it (as with the sacred wells)' (Lewis 1975:133; also see Smith 2008:14).

13.Damasio (2003:85) states that we have emotions first and feelings afterwards, because that was their evolutionary sequence. 'Emotions play out in the theatre of the body. Feelings play out in the theatre of the mind' (Damasio 2003:28, 30). of the body. Feelings play out in the theatre of the mind' (Damasio $2003: 2$
He views feelings as perceptions supported by the brain's body maps.

14.Jung regards superstition as a fundamental feature of the human psyche. He maintains that despite a century and a half of rationalism belief in spirits and similar manifestations is rife amongst most people (Jahoda 1969:65) 
premise is that human behaviour is natural if it is consonant with insights arrived at in that epoch. Therefore, it is not natural to believe that the earth is flat if we can prove that it is spherical. Acceptance of supernatural reality cannot be proven to be unnatural at present, but claims to its alleged 'effects' can. We know that all people have some sort of irrational belief at one time or another. Dogma or wielders of institutional power do not determine the role of superstition in a given era, as is the case with organised religion, but simply by 'currency', popularity and the fact that it meets some need. We do not readily acknowledge our own superstitions, but are quick to reject those of other people. In other words, superstition changes dynamically all the time.

In this article, superstition is considered natural in the sense that our insight into the nature of the human psyche 'permits' it. It is not seen as natural because it contains no contradictions or untruths, but because it is a product of human thought, like every other cultural product. ${ }^{15}$

Superstition is older than formal religious faith. It is the womb in which faith 'grew'; ${ }^{\prime 6}$ historically it antedates faith (read formal religion), but to this day it occurs in and alongside formal religion. In that sense superstition is natural and theology (i.e. complex metaphysical dogma) is unnatural. Everyday faith or superstition operates at an instinctive, naïve level rather than on a rational, discursive plane (reminiscent of Wolpert's [1993: 31-34; 172ff] distinction between the 'naturalness' of technology and the 'unnaturalness' of science). Seen thus, superstition is as spontaneous and 'false' as the perceptions, urban myths and everyday opinions that people fervently espouse without any proof Organised religion did not supersede superstition (superstition is not a religion, although religions contain superstitions). Organised religion did; however, secure a monopoly in interpreting reality as a result of power constellations that were erected ${ }^{17}$ (contract with the state; influence of temples, books, dogmas that were devised; indoctrination). ${ }^{18}$

Arguably religion could never have survived without superstition. Superstition accepts that powers beyond and outside human beings determine their lives and that if those beliefs were to die, religion could not exist. To say that religion evolved from superstition is as incorrect as to say that science evolved from alchemy. But superstition was part of our forebears' broader culture, without which it could not have evolved. What is true is that religion acquired its hold

15.Jahoda (1969:69) points out that both Freud and Jung 'agree that superstitious beliefs and practices are deeply rooted in man's unconscious mental processes; both held that superstition is not a thing of the past, or confined to the less educated - in fact it is regarded as part and parcel of everybody's mental make-up, educated - in fact it is regarded as part and parcel of everyb
liable to come to the surface under certain circumstances'.

16.Dennett $(2006: 140,167 \mathrm{ff})$ sees folk religion as the matrix of organised religions: 'Before any of the great organized religions existed, there were folk religions, and these provided the cultural environment from which organized religions could emerge'. Thus organised religion is a by-product of superstition.

17.About 5500 years ago chiefdoms started merging into states, which permitted increased food production, which in turn led to the establishment of fixed trades and the emergence of scribes, bureaucrats, politicians, etcetra. Organised religion emerged alongside these things. One of its key functions was to ensure the divine right of the ruler (monarch) (see Shermer 2004:33 ff).

18.Dawkins questions the possibility of religion as an evolutionary mechanism, because it offered humans a better chance of survival. He advances the implausible theory that religion is a product of a 'misfiring' of the brain, something that might happen in individual instances, but not amongst an entire population group simultaneously (Dawkins 2006:174, 179). on people because they are susceptible to superstition. If you were to remove the superstitious elements from religion and keep only its dogmatic, metaphysical systems (pure doctrine) it would be interesting to see what following one would retain. Amongst the superstitious elements incorporated into religions are belief in miracles, guilt and the consequent fear of catastrophe (punishment, hell) (see Hume 1978:439, 446-447), reward (a long and happy life, life after death), and a blueprint for living. These are also the basic elements of superstition.

Superstition, then, is natural and thrives in the 21st century. It occurs universally regardless of language, culture, race or level of development. Commonly cited examples are the growing faith in homeopathic medicine (Claassen 2007:23; Park 2008:142-160), the multibillion rand gambling industry, and New Age beliefs (with 'synchronicity' as a common denominator), all sorts of unprovable applications of the principle of quantum mechanics (Park 2008:129-141), and creationism (Claassen 2007:56-63, 121-125; Dawkins 2006:15-128; Dennett 2006:61-62). Park (2008:124) cites the following superstitions arising from the New Age movement: 'embraced spiritism, reincarnation, channelling, mediums, holistic healing, astrology, crystals, pyramid power'.

Superstitions appear to be more volatile than faith and reflect the fashions of the time. It has more latitude to adjust to the spirit of the age, because it is free from dogmatic and doctrinal constraints. The upsurge of secular spirituality in the West may simply be 'updated' superstition. Religion is less dynamically fluid, because churches, mosques and synagogues jealously guard their body of fixed religious propositions. Even more embarrassing for churches is superstition's takeover of certain 'dated' aspects of religion, then taking these to absurd extremes - and it works! Examples are the many films and film series about angels, devils and demons, evil forces, communication with the dead ('Crossing over' programme), films on healings, programmes on spirituality and synchronicity. These are presented alongside films based on sheer superstition (e.g. about vampires and aardwolves, astrology, etc.). Superstition does not decline with increased 'technologisation' of our life world; indeed, technology simply becomes instrumental in heightening superstition. Consider, for example, how Heisenberg's uncertainty principle and certain aspects of quantum mechanics have been used in recent times to offer all sorts of religious explanations whose basic traits do not differ that much from a system of superstitions. In addition, superstitions have mushroomed around computer technology such as all the things computers will be able to do one day.

\section{Attempts to demonstrate the naturalness of religion Religion and superstition are natural}

Both religion and superstition are rooted in human rationality and physicality. Viewed 'objectively' there is no difference between the two, in that both make claims that cannot be proven. Jahoda (1969:9) affirms this: '[I]t ought to be evident 
by now that there is no objective means of distinguishing "superstition" form other types of belief and action'. Both faith and superstition occur universally. Jahoda (1969:33) categorises the world's people not as superstitious and enlightened, but at most as more or less superstitious.

One thing religion and superstition have in common is that both posit a supernatural reality that supervenes on this world; either that, or reality itself is regarded as inherently supernatural. Supernatural reality harbours agents. They could be personal powers of good and evil (gods, demons, ghosts, witches, witchcraft and magical powers); or impersonal, 'fateful' or 'cosmic' forces (fate, destiny, astrology and synchronicity). Both religion and superstition link the subject with supernatural reality in some way, either positively or negatively. The argument is that the divide between the two worlds can be bridged by communicating with the powers (e.g. via prayer, states of trance or ecstasy, mediums, meditation, mystical practices, religious ecstasy, shamanic dream journeys, etc.). Do humans create the powers and the 'distance' between them simply to take on the challenge of bridging it? In mysticism the divide between the terrestrial and the super-terrestrial, time and eternity is bridged and the person becomes one with the Absolute (the experience of Absolute Unitary Being [AUB], that is, union with the godhead, which is a brain function). Apart from communication, the chasm is also bridged through all sorts of rituals that influence (manipulate) the supernatural, call it forth, and so on. It can also be 'bridged' rationally by way of some theory (dogma) that usually displays metaphysical features.

For faith and superstition to work, you have to 'believe'. In both cases it presupposes some knowledge, accompanied by trust (in the truth of what you believe). In religion belief is elevated to a supernatural capacity - something that is infused into you (gratia infusa). The aim is to secure the transcendent and uphold the uniqueness of such faith. Yet faith is a normal human brain function, in which things (including unsee-able, supernatural things) are taken to be true. That is inconceivable without the normal functioning of rationality and the concomitant emotion - hence normal brain functions. The exceptional function of religious faith has to do with religious power. To the lay believer her faith, just like her superstition, is not a category of truth but of being (Žižek 2003:42).

\section{The role of emotion}

It is one thing to say that religion and superstition are natural and permeate our thinking and affect. It is quite another to reconcile them with a scientific worldview that leaves no scope for the supernatural. But if we accept that they are natural, it means that people are responsible for their own beliefs and superstitions. ${ }^{19}$ The yardstick for that responsibility is the insight that historical development provides. In light of modern scientific knowledge, do religion

19.'Man philosophizes because he is in trouble. And he is always in trouble. He is always longing for self-integration and harmony, in the light of which ideals he feels their lack in his finite situation' (Hegel 1959:34). and superstition still make sense? The underlying assumption is that basic human needs remain the same (supported by concomitant rationalisations, which in their turn are backed by corresponding emotions), but are expressed differently in light of fresh insight. In other words, should the needs accommodated by religion and superstition not be rephrased in a scientifically accepted 'idiom'? This is only happening sporadically in specialised contexts like the science-religion debate. Maybe the latitude offered by science is simply too confined to allow the human mind (emotion) sufficient leeway. Experiences of guilt, for instance, are more readily accommodated in religion and superstition than in a scientific context, where emotions are usually denigrated.

But let us return to the question how experience of the supernatural differs in religion and superstition, or by the same token, anything else we experience and assume to be true. In either case people arrive at 'insight' by truly experiencing something they believe to be true. ${ }^{20}$ The same cognitive modalities are activated in the process of understanding, whether it is an article of faith or a superstition (only the alleged agents involved may differ).

Experience, feeling and emotion play a major role in human thought, including human faith and superstition. ${ }^{21}$ Other psychological factors like suggestion, expectation and intentionality cannot be left out of account. Smith makes the following point:

Virtually all who write about superstition at some point allude to the affective states that inspire it: to the ways in which, for example, situations of uncertainty or social strain give rise to feelings of anxiety, vulnerability, or envy.

(Smith 2008:43)

This inevitably raises the question of the explanatory role of psychological notions in this regard. To Jahoda (1969:3) emotion is basic to superstition, 'since it would otherwise fail altogether to affect behaviour, and thus not be very interesting'. The same may be said about faith. Without emotion and personally evocative appropriation of events the religious subject remains unaffected. The emotional aspect of superstition complicates rational evaluation (a problem Schleiermacher also encounters in a religious context). It cannot be researched, says Gordon (2008:76): 'Since the charge of superstition operates by arousing an essentially emotional response, the logical basis of the claim is protected from examination'.

What is important is the role of emotion in rationality something that has always been relegated to the backseat, because emotion resists epistemological analysis. Does

20.James (1994:549), who uses the term 'faith-state' for the role of both the biological and the psychological dimensions in human experience: 'The total absence of it anhedonia, means collapse'. When this 'faith-state' is associated with intellectua content, it engenders passionate loyalty to an article of faith, something people will hold out for to the death. Accordingly, James rates it 'amongst the most important biological functions of mankind' (see James 1994:549-550).

21.With reference to rites Wittgenstein (1979:13) writes: 'The most noticeable thing seems to me not merely the similarities but also the differences throughout all these rites. It is a wide variety of faces with common features that keep showing in one place and in another. And one would like to draw lines joining these parts that various faces have in common. But a part of our contemplation would still be that various faces have in common. But a part of our contemplation would still be
lacking, namely what connects this picture with our own feelings and thoughts. This part gives contemplation its depth'. 
experience evoke belief or the other way round? Whereas the hermeneutic circle seeks to understand by focusing purely on the thought process, a hermeneutics of consciousness has to look at the circular sequence of knowledge and experience: what we experience and especially how we experience it (role of emotion) determine the formation of what we 'believe to be true' (knowledge component). What I experience determines what I take to be true; at the same time what I take to be true determines what I experience (emotion). Harris (2004) comments:

The power that belief has over our emotional lives appears to be total. For every emotion that you are capable of feeling, there is surely a belief that could invoke it in a matter of moments.

(Harris 2004:52)

After all, human emotion is natural (purely electrochemical processes), not supernatural. At the same time emotion plays a cardinal role in our experience of transcendence, as well as in our subsequent insistence that what we experienced was transcendent (supernatural). Hence, we must accept as natural the human potential to experience (and create) the imaginative and the supernatural in the organ intent on interpreting all that comes its way, the human brain.

In a secularised environment many people no longer believe either religion or superstition to be true but see them as beneficial. The naturalness of both does not mean that they are true, but that they 'work' for human beings - just as the placebo effect 'works'. Žižek (2006:30) mentions that Bohr hung a horseshoe on his front door. Asked whether he, a scientist, believed the superstition that it brings luck, he answered he did not - but added that even if you do not believe it, it still works.

That is an apt description of the operation of religion and superstition in a secularised environment. Neither has been committed to permanent oblivion, but a certain critical distance has been created: 'Today we ultimately perceive as a threat to culture those who live their culture immediately, those who lack a distance toward it' (Žižek 2003:7). The cynical distance many people insist on is not always to be trusted. Hence what is odd is not:

that people do not 'really believe', and act upon their professed principles, but that people who profess their cynical distance and radical pragmatic opportunism secretly believe more than they are willing to admit.

(Žižek 2003:8)

And, we may add, that applies to religion and superstition alike. People believe in their religion. It is a matter of believing in one's (doctrinal) faith and believing in faith as such (being the 'open sesame' to salvation, for 'faith in' is the magic formula) (Dennett 2006:290ff).

There are many practices that modern, secularised people would dismiss as ludicrously superstitious. But there is also a fair body of stories, claims and practices that may well be superstitious and which we regard sceptically without rejecting them outright. We keep many ideas in our 'mental limbo' just in case something happens that confirms them. We do not really believe the idea, but neither do we want to 'let go of' it. We have outgrown our religious and superstitious scaffolding, but we refuse to demolish it.

Smith (2008) writes:

The advance of science, however, has not led to the complete discrediting of religion: rather it has forced a redefinition of its sphere of competence from all-encompassing cosmology to a discourse concerned with questions of ultimate meaning and moral value. Moreover, it is not the scientific account of the world per se that has weakened supernatural understandings of the cosmos so much as the application of science to the natural and social worlds. ${ }^{22}$

(Smith 2008:53)

Modern atheism functions in tandem with science. The element of control cannot be ruled out. Science wants to control truth, for it has made the empirically demonstrable the fulcrum. It is a natural attribute of human beings that in the face of ignorance they want to be lords of their circumstances and control them as best they can. That is the rationale of superstition and religion. Final knowledge means control (via closure) and we know that the human spirit cannot breathe in that confined space. That is why we move from the known to the unknown where our control is less restrictive.

An instance of control is the equivocal way in which scientists inveigh against religious fundamentalism but at the same time reject postmodernism, which relativises literalism and puts fundamentalism on shaky ground. Fundamentalism represents 'superstitious control' and postmodernism represents scientific 'noncontrol' and provisional 'truth'. Scientists cannot handle either. The standard argument against postmodernism and other forms of relativism is that they are absolute (cf. the absolute maxim, 'everything is relative'). Throwing out the baby with the bathwater does not serve the cause of science. Postmodernism is essential to show up the layered, historical, provisional, interdependent and interrelated nature of all knowledge. This caveat is not heeded in the radical rejection voiced by many scientists (e.g. Gross \& Levitt 1994;, ${ }^{23}$ Sokal 2008; ${ }^{24}$ Harris $2004^{25}$ ).

\section{Factors in contemporary risk societies that are conducive to both faith and superstition}

What modernism did to our human self-image was to establish a sense of rational control. That control was not confined to the objective world but extended to the

22.Illuminating, in this regard, is Žižek's reference (2003:47) to Chesterson's claim that the irrationality of the late 19th century was a result of the rationalist (Aufklärung) onslaught on religion.

23.Gross and Levitt (1994:71) rightly refuse to see postmodernism as a 'body of ideas', 'for postmodernism is more a matter of attitude and emotional tonality than a rigorous axiomatics'. Yet they forget this in their critique of postmodernism, where they equate it with pseudo-science (see p. 89ff). Probably postmodernism is less applicable to 'hard-core' science, but it is indispensable in the human sciences, for applicable to hard-core' science, but it is indispensable in the human sciences, for 'closure' when it comes to truth.

24.See especially p. $263 \mathrm{ff}$.

25. Harris (2004:178) feels that relativism is not overly critical of other people's beliefs. 'But most forms of relativism ... are nonsensical'. 
supernatural realm. In that way, we believed, we put paid to the worlds of spirits, angels, ghosts, all sorts of 'powers' in the sky and other irrational features of earlier cultures. We were in command of our own future. If people made an individual and a collective effort, they would be able to achieve most rational ideals and not be dependent on the powers of fate and supernatural forces to do so.

Present-day realities have smashed that optimism. Our world is unable to deal with poverty and corruption; AIDS, bird and swine flu remain threatening diseases; terrorism is an ongoing hazard; water shortage and food insecurity as a result of temperature change and pollution are real possibilities. Our forecasts are not always accurate (cf. tsunamis and the volcanic irruption in Iceland); often we can at most predict disasters and try to prepare ourselves for the consequences that are beyond our control. Sometimes things happen overnight. In a very short time the current economic recession has played havoc with thousands of people's job and retirement security. We are captives of our own manipulable and fickle monetary systems.

The chances are that apocalyptic menaces will regain their supernatural aspect. The common denominator amongst human beings is a sense of insecurity and exposure to risk. It is the outcome of our particular history. In South Africa we and our children face a future of picking the fruits of irresponsible mining that is polluting our water and agricultural produce. The systems (e.g. monetary, industrial) that we have created are too vast and intertwined to dismantle overnight. Our virtual world is exactly that: virtual. It is manipulable, unpredictable and ever changing (volatile). We have our business cut out to keep up with technology if we are not to lose our independence and influence. The days when the experts knew all the answers to our problems and were in control are gone. When the experts do know and issue warnings (e.g. Global warming), we refuse to respond, and expert opinions tend to differ, or are subordinated to the dictates of large corporations that pay for research.

Another common denominator is that 'sentiment' (intuition, emotion, affect) is emerging as the ally of rationality. It is market sentiment that determines the stock exchange. It is sentiment and perception that makes us see every Muslim as a terrorist and every well-heeled black man as corrupt. Sentiment and affect likewise play a major role in acceptance of new gods that govern our luck and fortunes. This is because of deep-seated anxiety; autonomous reason is no longer at the helm. It is 'dependent' on some catastrophe to give us the courage to implement emotionally driven change. We must limit growth, close down mines and industries, have fewer children, spend less, share more generously with the poor - but right now the price remains too high (unemployment, an economic recession, higher taxes, unstable governments). Only once the system crumbles and we face an even worse scenario will intuition be 'ripe' to add deeds to all those words. Everyone knows that we need to limit growth, but no one wants to be the first to do so. We comfort ourselves by playing with plans for recycling programmes. Bygone virtue ethics and new accents in an ethics of responsibility remain confined to futile bourgeois symbols. They are seized upon to give us the illusion that we are still somehow in control and do not have to give in to fatalism.

Do we not perhaps need a 'new modernity'? It is not a matter of doing away with control but of exercising better, maybe even more stringent control. We need to have greater control over greed and selfishness! Until such time as the era of uncertainty and sense of unpredictability, mistrust and risk is past we can expect new faiths and superstitions to burgeon as emotive placebos for our fears. Every belief and superstition matches the challenges of its age. In that sense we cannot speak of better or worse beliefs and superstitions. They are simply part of the human condition and expressive of our attempt to arrive at a holistic understanding and a sense of unity with our world.

\section{Conclusion}

Originally faith and superstition were fairly closely linked. Later they parted ways as a result of the power that institutionalised religion gained. The immanent life world of naïve experience and the daily struggle for survival, bolstered by characteristic superstitions, was separated from the transcendent world of theologians, characterised by metaphysical notions of absolute, final truths. Although the two worlds differ dramatically, it is a moot point whether the patterned connections created at the immanent level differ all that much from the patterned connections at the transcendent level. Of course the latter form part of a closed metaphysical system, hence are more systematic and logically coherent than the former. What the two worlds have in common is that their inhabitants found their notions meaningful.

The headlong advance of Enlightenment thought increasingly eroded the closed world of metaphysical constructions 'from below' via historical, redaction and textual criticism, philosophical criticism of metaphysics, and development in the physical sciences. The metaphysical world must perforce fall back on the immanent sphere, still fraught with patterned, 'unprovable' connections that are dismissed as superstitious by the scientific fraternity. Theology has to be revamped and a more sensible approach is to find transcendence in immanence, more especially in human biological nature with its thought processes that permit immanent transcendence.

So we have come full circle. At first superstition and faith were inseparable. Religion then parted ways with superstition by allying itself with political powers and developing texts, cults and dogmas. From its transcendent sphere of knowledge and truth it looked down on the world of superstition. The ignorance of the superstitious was exploited to shackle them to the guardians of truth and restricting them to the outer perimeter of truth. Then came the enlightenment of the secular world by science and technology, precipitating the collapse of metaphysical constellations and a return from the realm of transcendent absolutes to immanence. The link at the immanent level lies in the shared needs that have 
always characterised the world of superstition. The world as an uncharted realm of consciousness is open and offers fresh scope for a transformed transcendence to flourish. But it is a this-worldly transcendence, in which both religion and superstition as human phenomena can claim to be natural in the face of scientific demands that they should be abolished. The article points out the naturalness of both faith and superstition in the context of human interpretive systems.

\section{References}

Berry, C.J., 1982, Hume, Hegel and human nature, Martinus Nijhoff, London, UK.

Boucher, G., Glynos, J. \& Sharpe, M., 2005, Traversing the fantasy. Critical responses to Slavoy Žižek, Ashgate, Aldershot, UK.

Boyer, P., 2001, Religion explained, Basic, New York, NY.

Calvin, J., (n.d.), Institutes of the Christian Religion, MacDonald, Florida, FL.

Claassen, G., 2007, Geloof, bygeloof en ander wensdenkery [Religion, superstition and other wishful thinking], Protea Boekhuis, Pretoria.

Damasio, A., 2003, Looking for Spinoza, Harcourt, New York, London.

Dawkins, R., 2006, The God delusion, Bantam, London, UK.

Dennett, C., 2006, Breaking the spell, Lane, Faber \& Faber, London, UK.

Frazer, J.G., 1943, The golden bough. A study in magic and religion, Macmillan, New York, NY

Freud, S., 2002, [1941], The psychopathology of everyday life, Penguin, London, UK

Gordon, R., 2008, 'Superstitio, superstition and religious repression in the late Roman republic and principate (100BCE-300CE)', in S.A. Smith \& A. Knight, The religion of fools, Superstition past and present, Oxford Journals, suppl. ser. 3.

Gross, P.R. \& Levitt, N., 1994, Higher superstition. The academic left and its quarrels with science, John Hopkins University Press, Baltimore \& London, UK.

Harris, S., 2004, The end of faith. Religion, terror, and the end of reason. Norton, New York, London.
Hegel, G.W.F., 1985, Lectures on the philosophy of religion. Vol. III The consummate religion. University of California Press, Los Angeles, CA.

Hegel, G.W.F., 1959, Encycpopedia of philosophy, transl. G.E. Mueller, Philosophical Library, New York, NY.

Hume, D., 1978, A treatise on human nature, revised by P.H. Nidditch, Clarendon, Oxford, UK.

Hume, D., 1963, Hume on religion, Collins, London, Glasgow, UK.

Jahoda, G., 1969, The psychology of superstition, Penguin, London, UK.

James, W., 2002, The varieties of religious experience, Modern Library, New York, NY.

Lakoff, G. \& Johnson, M., 1999, Philosophy in the flesh, Basic, New York, NY.

Lewis, D., 1975, Religious superstition through the ages, Mowbrays, London \& Oxford, UK.

Park, R. L., 2008, Superstition. Belief in the age of science, Princeton University Press, Princeton, NJ.

Ross, R.E., 1987, Hegel on irrationality: A critical examination of the myth, UM Dissertation Information Service, Michigan, MI.

Shermer, M., 2004, The science of good and evil, Owl, New York, NY.

Smith, S.A. \& Knight, A., 2008, 'The religion of fools. Superstition past and present', Oxford Journals, suppl. ser. 3.

Smith, S.A., 2008, 'Introduction', in S.A. Smith \& A. Knight A., 'The religion of fools. Superstition past and present', Oxford Journals, suppl. ser. 3.

Sokal, A., 2008, Beyond the hoax. Science, philosophy and culture, Oxford University Press, New York, NY.

Taylor, C., 1975, Hegel, Cambridge University Press, Cambridge, UK.

Wheen, F., 2004, How mumbo-jumbo conquered the world. A short history of modern delusions, Fourth Estate, London, UK.

Wittgenstein, L., 1979, Remarks on Frazer's Golden bough, Brynmill, Nottinghamshire, UK.

Wolpert, L., 2006, Six impossible things to do before breakfast. The evolutionary origins of belief, Faber \& Faber, London, UK.

Wolpert, L., 1993, The unnatural nature of science, Faber \& Faber, London, Boston.

Žižek, S., 2006, How to read Lacan, Norton, New York, NY.

Žižek, S., 2003, The puppet and the dwarf, MIT, Cambridge (MA), London, UK. 